\title{
PLANO DE TRATAMENTO COM PROGNÓSTICO DUVIDOSO, EM DENTES MOLARES SUPERIORES COM FÍSTULA
}

Vanessa Sanglard de SOUZA, Gilson Blitzkow SYDNEY, Antonio BATISTA, Tatiana Miranda DELIBERADOR, Marili Doro Andrade DEONIZIO

O diagnóstico de doenças é importante no plano de tratamento odontológico. O objetivo deste trabalho foi identificar a origem da fístula e a possibilidade de manutenção do dente na arcada através da remoção da raiz mésio-vestibular. A paciente S.R.M. na anamnese, relatou inchaço extra-oral na região do dente 26; ao exame clínico detectou-se fístula vestibular e coroa onlay sobre remanescente dentário e ao exame radiográfico tratamento endodôntico prévio, retentor intra-radicular, cone de guta-percha na região de furca, presença de lesão periapical na raiz mésio-vestibular e recidiva de cárie na face mesial. Para identificação da origem da fístula removeu-se seqüencialmente: a coroa, o pino intra-radicular, o material obturador das entradas dos canais e verificou-se no assoalho da câmara pulpar a ausência de perfuração, de fratura e do quarto canal na raiz mesio-vestibular. Após incisão cirúrgica e descolamento de retalho observou-se a presença de lesão entre as raízes vestibulares e após remoção do tecido de granulação encontrou-se comunicação da lesão com o seio maxilar. Optou-se por remover a raiz mesiovestibular para posterior retratamento endodôntico com reconstrução protética para manutenção do dente na cavidade oral.

Palavras- Chave: Raiz Dentária; Defeitos da Furca; Canal Radicular 